\title{
O PIBID E A FORMAÇÃO INICIAL DE PROFESSORES: UMA EXPERIÊNCIA NA ELABORAÇÃO DE ROTEIROS DE ATIVIDADES PEDAGÓGICAS
}

\section{THE PIBID TO INITIAL FORMATION TEACHERS: AN EXPERIENCE IN ELABORATION OF THE SCRIPTS PEDAGOGICAL ACTIVITIES}

\author{
OLIVEIRA, Elaine Toná de ${ }^{1}$ \\ ZANATTA, Shalimar Calegari ${ }^{2}$ \\ ROYER, Marcia Regina ${ }^{3}$ \\ LORO, Alexandre Paulo ${ }^{4}$
}

\begin{abstract}
RESUMO
O objetivo foi evidenciar a importância do Programa Institucional de Bolsas de Iniciação à Docência (Pibid), tendo como suporte de análise uma vivência do subprojeto de Ciências Biológicas da Universidade Estadual do Paraná, campus Paranavaí. A vivência foi organizada em dois momentos: 1) leitura da Base Nacional Comum Curricular com ênfase nos conteúdos de Ciências e Biologia; 2) planejamento de atividades práticas, roteiros, modelos e jogos didáticos. Foram produzidos quatro roteiros de atividades. Como resultados foram produzidas duas sínteses de análise organizadas na categoria "Características dos roteiros de atividades pedagógicas", abrangendo as subcategorias "Estratégias iniciais: ponto de partida" e "Estratégias de aplicação dos conteúdos". Assim, verificou-se que o Pibid promove situações que estimulam o pensar e o repensar da prática, bem como a reflexão e relação entre teoria e prática e, por isso, contribui positivamente para o processo de formação inicial de professores.
\end{abstract}

PalaVRas-Chave: Formação inicial de professores; BNCC; Atividades pedagógicas; Análise de conteúdo.

\section{ABSTRACT}

The objective was to highlight the importance of the Institutional Teaching Initiation Scholarship Program (Pibid, in Portuguese), supported by an analysis of the Biological Sciences subproject of the Paraná State University, Paranavaí campus. The experience was organized in two moments: 1) reading of the Common National Curriculum Base with emphasis on Science and Biology contents; 2) planning of practical activities, scripts, models and

\footnotetext{
${ }^{1}$ Universidade Estadual do Paraná (UNESPAR). Secretaria da Educação e do Esporte do Paraná (SEEDPR). Paranavaí, PR, Brasil. ORCID: https://orcid.org/0000-0003-4827-5751 e-mail: elainetona.oliveira@gmail.com

2 Universidade Estadual do Paraná (UNESPAR). Paranavaí, PR, Brasil. ORCID: https://orcid.org/00000003-0302-8300 e-mail: shalicaza@yahoo.com.br

3 Universidade Estadual do Paraná (UNESPAR). Paranavaí, PR, Brasil. ORCID: https://orcid.org/00000002-6369-9440 e-mail: marciaroyer@yahoo.com.br

${ }^{4}$ Universidade Federal da Fronteira Sul (UFFS). Chapecó, SC, Brasil. ORCID: https://orcid.org/00000002-4207-7642 e-mail: alexandrepauloloro@yahoo.com.br
} 
DOI: $10.12957 / \mathrm{e}-\mathrm{mosaicos} .2020 .47233$

educational games. Four itineraries of activities were produced. As results, two analysis summaries were produced, organized in the category "Characteristics of the scripts of pedagogical activities", covering the subcategories "Initial strategies: starting point" and "Strategies of application of the contents". Thus, it was found that Pibid promotes situations that stimulate the thinking and rethinking of practice, as well as the reflection and relationship between theory and practice, and therefore contributes positively to the process of initial teacher training.

KEYWORDS: Initial formation of teachers; BNCC; Pedagogical activities; Analyze of the Content.

\section{INTRODUÇÃO}

A formação inicial de professores tem se constituído importante tema de debates no meio acadêmico haja vista o número significativo de trabalhos de pesquisa que abrange esta temática. Tais pesquisas tratam principalmente dos desafios que envolvem a formação desses profissionais e a necessidade de rever os aspectos que são considerados essenciais para a prática docente.

Com o intuito de atender a demanda da melhoria da qualidade da formação inicial dos professores e como Política Nacional de Formação de Professores da Educação Básica, foi criado o Programa Institucional de Bolsas de Iniciação à Docência (Pibid) pelo Ministério de Educação (BRASIL, 2016). Financiado pela Coordenação de Aperfeiçoamento de Pessoal de Nível Superior (Capes), o Pibid está direcionado a acadêmicos de cursos de licenciaturas em Instituições de Ensino Superior (IES), públicas e/ou privadas, a fim de fomentar a criação de projetos que promovam a iniciação à docência.

O programa oferece bolsas de estudos para acadêmicos que estejam na primeira metade do curso e contempla todos os componentes curriculares. A concessão de bolsas é "uma estratégia para a efetividade do processo de indução e fomento à valorização e à qualificação da formação inicial de professores para educação básica" (BRASIL, 2018a, p. 1).

Organizado num sistema de parceria entre as IES e as escolas da Educação Básica, o Pibid tem por objetivos,

I. Incentivar a formação de docentes em nível superior para a educação básica;

II. contribuir para a valorização do magistério;

III. elevar a qualidade da formação inicial de professores nos cursos de licenciatura, promovendo a integração entre educação superior e educação básica;

IV. inserir os licenciandos no cotidiano de escolas da rede pública de educação, proporcionando-lhes oportunidades de criação e participação em experiências metodológicas, tecnológicas e práticas docentes de caráter inovador e interdisciplinar que busquem a 
DOI: $10.12957 / \mathrm{e}-\mathrm{mosaicos} .2020 .47233$

superação de problemas identificados no processo de ensinoaprendizagem;

V. incentivar escolas públicas de educação básica, mobilizando seus professores como coformadores dos futuros docentes e tornando-as protagonistas nos processos de formação inicial para o magistério;

VI. contribuir para a articulação entre teoria e prática necessárias à formação dos docentes, elevando a qualidade das ações acadêmicas nos cursos de licenciatura (BRASIL, 2018b, p. 1).

Portanto, o programa visa a proporcionar ao discente uma aproximação entre a teoria e a prática, permitindo a vivência da realidade escolar desde o início de sua formação, possibilitando uma constante reflexão sobre teorias, metodologias e práticas pedagógicas.

Essa interação promove uma construção e reconstrução do professor em formação, uma vez que permite reflexões sobre sua prática em sala de aula, o que pode contribuir para o maior interesse pela docência (MORYAMA; PASSOS; ARRUDA, 2013).

Segundo relatório de Gestão do Pibid, realizado pela Capes, divulgado em 2013, houve uma grande evolução quanto ao número de bolsas concedidas e implantadas em todo o país, saltando de 3.088 bolsas em 2009 para 49.321 em 2013 (BRASIL, 2013).

Para avaliar os impactos do programa nas IES, nos cursos de licenciatura e nas escolas participantes, a Diretoria de Formação de Professores da Educação Básica, vinculada à Capes, elaborou formulários que foram preenchidos tanto pelos coordenadores institucionais e de gestão, quanto pelos coordenadores de área, supervisores e bolsistas de iniciação à docência. A partir das respostas obtidas pelos formulários verificou-se "que o Pibid, além de aumentar a qualificação da formação de professores, gera impactos diretos nas escolas de educação básica [...]" (BRASIL, 2013, p. 54), uma vez que contribui para a valorização do magistério na educação básica. O relatório também aponta que o programa tem se constituído,

[...] uma importante política pública com alto potencial de melhoramento dos cursos de licenciatura, justamente por inserir a formação no interior da escola e enfatizar a complexidade da formação de professores no debate e nas ações voltadas à profissionalização dos professores que atuarão nas escolas de educação básica (BRASIL, 2013, p. 54).

Observa-se, assim, que a proposta do programa e sua abrangência tem aproximado um grande número de IES e de escolas de educação básica, gerando um estreitamento nas relações de troca e cooperação entre a universidade. Tal fato é evidenciado pelo relatório divulgado pelo Ministério de Educação em 2018, ressaltando que apenas no ano de 2017 o Pibid destinou mais de 72.000 bolsas a projetos de iniciação à docência, que aproximaram cerca de 279 instituições formadora e mais de 
DOI: $10.12957 / \mathrm{e}-\mathrm{mosaicos} .2020 .47233$

5.500 escolas de educação básica. O programa contemplou 36 áreas de licenciatura, abrangendo todas as unidades federativas (BRASIL, 2018c).

No entanto, a continuidade do Pibid tem sido ameaçada mediante $o$ anúncio de cortes no orçamento da Capes. Nesse contexto, estamos vivenciando uma série de manifestações que tem ocorrido em todo o país em prol da manutenção da concessão do número de bolsas e, consequentemente, para a continuidade do Programa. Tais manifestações envolvem professores das IES, coordenadores e supervisores do Pibid, bem como bolsistas, acadêmicos dos cursos de licenciatura e representantes da educação básica. Essas mobilizações apontam a importância do Programa diante das contribuições que tem gerado para a melhoria na formação inicial e no processo de ensino e aprendizagem de grande número de estudantes do país.

\section{SUBPROJETO DE CIÊNCIAS BIOLÓGICAS DA UNESPAR}

Segundo as orientações do Edital no 7/2018 da Capes (BRASIL, 2018b), as IES interessadas em participar do programa devem, entre outras obrigações, apresentar um Projeto Institucional de Iniciação à Docência, conforme especificações contidas no documento. A partir desse projeto é formulado o subprojeto que, segundo o inciso III do item 2.3.5., "corresponde ao conjunto de núcleos de iniciação à docência agrupados por componente curricular ou curso".

O subprojeto focado nessa pesquisa é o de Ciências Biológicas da Universidade Estadual do Paraná - UNESPAR, campus de Paranavaí, município de Paranavaí (PR), que atua em duas escolas estaduais do município. É composto por 16 licenciandos bolsistas e 4 voluntários, 2 supervisoras (professoras da escola pública), 1 coordenadora de área e 1 coordenadora de área voluntária. Esse subprojeto define as atividades que devem ser realizadas por cada membro do programa.

Cada licenciando participante deve cumprir um total de 32 horas mensais em relação aos afazeres do projeto. A carga horária está distribuída de maneira formativa e evolutiva, uma vez que estabelece atividades específicas para cada momento do projeto. No período inicial são promovidas atividades voltadas para a preparação dos acadêmicos, compreendendo estudos dirigidos e encontros na IES. Nessa etapa é relevante destacar que uma das tarefas previstas é o estudo da Base Nacional Comum Curricular (BNCC), documento norteador da educação básica do Brasil. Esse documento define as aprendizagens essenciais para a educação infantil, o ensino fundamental e o ensino médio e teve sua aprovação completa em 2018, porém não implantada até o momento (BRASIL, 2018d).

O Pibid também prevê o cumprimento de uma carga horária nas escolas, a fim de conhecer a infraestrutura e o projeto político pedagógico para posteriormente participar de atividades pedagógicas em sala de aula. Importante ressaltar que os encontros na IES ocorrem ao longo de todo o desenvolvimento do programa, abrangendo estudos, planejamentos, orientações e compartilhamento de experiências. 
DOI: $10.12957 / \mathrm{e}-\mathrm{mosaicos} .2020 .47233$

Dentre as ações previstas para as supervisoras cabe citar o auxílio no direcionamento das atividades a serem desenvolvidas pelos participantes do projeto, além da atuação como coformador dos discentes, encaminhando o processo de construção de todas as atividades a serem desenvolvidas no ambiente escolar, bem como a articulação com a comunidade escolar para o bom andamento das atividades do Pibid.

À coordenadora de área cabe a orientação e correção de planos de aula e artigos, a orientação e o acompanhamento do planejamento de atividades a serem aplicadas na escola, além de ter a função de estimular a participação dos pibidianos em eventos e confecção de resumo, a condução reuniões periódicas e o recolhimento das fichas de atividades realizadas pelos participantes do projeto. É relevante salientar que esse espaço representa a única oportunidade dos acadêmicos em rever ou mesmo estudar pela primeira vez conteúdos de Ciências.

É importante destacar que as atividades estabelecidas no subprojeto estão atreladas ao objetivo de elevar a qualidade da formação docente por meio de ações conjugadas voltadas à formação inicial de professores nos cursos de licenciatura em Biologia.

Considerando o contexto apresentado, este artigo tem como objetivo evidenciar a importância do programa Pibid por meio do subprojeto de Ciências Biológicas da Universidade Estadual do Paraná - UNESPAR, campus de Paranavaí para a formação inicial dos professores. Para isso, relatamos uma experiência de minicurso desenvolvida nesse subprojeto e os resultados das análises do conteúdo de roteiros de atividades pedagógicas produzidas durante esse encontro.

\section{Procedimentos metodológicos}

Como apontado, esta pesquisa é resultado de uma experiência vivenciada durante a realização de um encontro com os pibidianos no campus da IES, na ocasião foi proposto um minicurso intitulado "Conhecendo a BNCC: estudo e reflexão sobre o conteúdo e estrutura do documento". As ações desenvolvidas foram planejadas com o intuito de contemplar duas atividades específicas para os licenciandos que estão previstas no plano de atividades para o campus da IES.

Ressaltamos que dentre as atividades desenvolvidas com os pibidianos, relatamos inicialmente como foi realizado o estudo da BNCC, para o ensino fundamental, séries finais, do componente de Ciências, que corresponde a etapa de atuação da maior parte dos pibidianos. Posteriormente apresentamos a maneira que foi conduzida uma atividade de elaboração de roteiros de atividades pedagógicas pelos licenciandos, com uso de recortes da BNCC do componente de Ciências para o ensino fundamental (EF).

Dentre as tarefas estabelecidas no subprojeto abordado foram selecionadas as seguintes: 1) leitura da BNCC com ênfase nos conteúdos de Ciências e Biologia; 2) planejamento de atividades práticas, roteiros, modelos e jogos didáticos. 
DOI: $10.12957 / \mathrm{e}-\mathrm{mosaicos} .2020 .47233$

A escolha da primeira está atrelada a necessidade de se conhecer e entender a estrutura, organização e conteúdo da versão aprovada da BNCC. De caráter norteador, esse documento será uma importante referência para a construção dos currículos e a formação dos professores de todo o país, o que refletirá direta ou indiretamente na abordagem e prática pedagógica em todas as escolas brasileiras.

Para Gasparin (2012), é fundamental conhecer a percepção e realidade dos alunos para desenvolver um trabalho mais adequado, que venha a promover um conhecimento significativo para esses sujeitos. Portanto, consideramos como ponto de partida para a realização das atividades a realidade vivenciada pelos licenciandos, a fim de aproximar a proposta de trabalho aos conhecimentos previamente construídos pelos pibidianos.

Concordamos que é fundamental a preocupação com a qualidade da formação inicial dos professores e que "preparar o professor para ensinar implica em prepará-lo para refletir sobre o próprio ensino, iniciando-o nos processos de investigação, por intermédio do estabelecimento efetivo da relação teoria-prática" (BELTRÃO; KALHIL; BARBOSA, 2017, p. 81). Orientados por essa perspectiva, justificamos a importância da segunda proposta de trabalho, uma vez que além de atender a um dos objetivos do programa, promove a possibilidade de criar atividades que estabeleçam uma relação entre a teoria e prática.

A atividade de planejamento de atividades práticas, roteiros, modelos e jogos didáticos, proporciona o exercício de pensar e repensar as ações pedagógicas, o que promove a melhoria da formação inicial dos professores. Como assevera Beltrão, Kalhil e Barbosa (2017), na pesquisa que desenvolveram sobre PIBID/CESP/UEA de Matemática, tais atividades promovem experiências metodológicas muito positivas, pois ao agregarem novos saberes e orientam ações que podem contribuir para a superação de problemas que envolvem o processo de ensino e aprendizagem.

Seguindo essa perspectiva, o encontro foi dividido em quatro momentos distintos, porém complementares conforme descritos no Quadro 1.

Quadro 1. Síntese das atividades realizadas com os pibidianos durante o Minicurso.

\begin{tabular}{|l|l|}
\hline \multicolumn{1}{|c|}{ Plano de trabalho } \\
\hline Momento 1 & $\begin{array}{l}\text { Estudo dirigido sobre a estrutura, organização e composição da BNCC } \\
\text { para o Ensino Fundamental, séries finais. }\end{array}$ \\
\hline Momento 2 & $\begin{array}{l}\text { Orientação sobre a forma de elaboração de um roteiro de atividades } \\
\text { pedagógicas com base em objetivos de aprendizagens previstos para o } \\
\text { componente de Ciências na BNCC, para o Ensino Fundamental, séries } \\
\text { finais. }\end{array}$ \\
\hline Momento 3 & $\begin{array}{l}\text { Organização dos pibidianos em grupos para a elaboração dos roteiros de } \\
\text { atividades pedagógicas. }\end{array}$ \\
\hline Momento 4 & $\begin{array}{l}\text { Socialização dos roteiros de atividades pedagógicas elaborados pelas } \\
\text { equipes para o grande grupo, seguido de espaço para contribuições dos } \\
\text { participantes. }\end{array}$ \\
\hline
\end{tabular}

Fonte: Autores. 
DOI: $10.12957 / \mathrm{e}-\mathrm{mosaicos} .2020 .47233$

Para a realização do estudo dirigido sobre a BNCC foi elaborado um material de apoio disponibilizado para cada participante contendo o que vem a ser o documento, suas finalidades, os marcos legais para sua construção, o processo de elaboração, sua relação com os currículos escolares, forma de organização em competências e habilidades, competências gerais, estrutura da Educação Básica e seus componentes, as áreas de conhecimento e esquema explicativo para compreender a estrutura dos códigos das habilidades.

Disponibilizamos um modelo de roteiro de atividade pedagógica com os seguintes itens: identificação dos integrantes da equipe, especificação do componente curricular e série/ano, dos objetos de aprendizagem e habilidades contempladas, número de aulas previstas para aplicação, materiais e recursos necessários, forma de organização da turma, descrição das atividades pedagógicas propostas e forma de avaliação.

Os pibidianos foram organizados em equipes com no máximo cinco integrantes. Este número limite foi definido com o intuito de possibilitar que todos tivessem a oportunidade de expor suas ideias de modo satisfatório. Importante destacar que as duas supervisoras do projeto constituíram uma equipe distinta para que não influenciassem no processo de elaboração dos roteiros de atividades pedagógicas dos licenciandos.

Na etapa de construção dos roteiros de atividades pedagógicas cada equipe recebeu um exemplar do modelo supracitado, juntamente com um quadro contendo um recorte da BNCC, EF, séries finais, sendo constituído pelo componente curricular de Ciências, o ano, a unidade temática e seus respectivos objetos de conhecimento e habilidades. Foram disponibilizados 4 quadros diferentes, sendo 2 específicos para 0 70 ano e dois para o $8^{\circ}$ ano do EF.

A equipe 1 recebeu o quadro A com o recorte da BNCC para o $7^{\circ}$ ano, sendo composto pela Unidade Temática "Vida e Evolução", que abrangem os objetos de conhecimento "Diversidade de ecossistemas; Fenômenos naturais e impactos ambientais; Programas e indicadores de saúde pública" (BNCC, 2018, p. 346-347).

A equipe 2 recebeu quadro $B$, também com o recorte para o 70 ano, porém era referente a Unidade Temática "Terra e Universo", abordando os objetos de conhecimento "Composição do ar; Efeito estufa; Camada de ozônio; Fenômenos naturais (vulcões, terremotos e tsunamis); Placas tectônicas e deriva continental" (BNCC, 2018, p. 346-347).

Os quadros $C$ e $D$ possuíam recortes para $8^{\circ}$ ano, distribuídos para as equipes 3 e 4 respectivamente. $\mathrm{O}$ quadro $\mathrm{C}$ era constituído pela Unidade Temática "Matéria e Energia", com os objetos de conhecimento "Fontes e tipos de energia; Transformação de energia; Cálculo de consumo de energia elétrica; Circuitos elétricos; Uso consciente de energia elétrica" (BNCC, 2018, p. 348-349). Já o quadro D abordou a Unidade Temática "Terra e Universo" e os respectivos objetos de conhecimento "Sistema Sol, Terra e Lua; Clima" (BNCC, 2018, p. 348-349). 
DOI: $10.12957 /$ e-mosaicos.2020.47233

Importante destacar que a BNCC atribui para cada objeto de conhecimento uma ou mais habilidades específicas. Tais habilidades indicam para o professor o que o aluno deve ser capaz de realizar dentro daquele objeto de conhecimento, operando como uma orientação na definição dos aspectos a serem trabalhados e da metodologia a ser adotada.

Assim, para a elaboração dos roteiros de atividades, cada equipe fez a escolha de duas habilidades dentre as elencadas nos quadros. A partir dessa definição os integrantes elaboraram os roteiros, contemplando os itens mencionados no modelo. Posteriormente as produções foram socializadas para o grande grupo, com o intuito de promover a troca de ideias, bem como a reflexão acerca da relevância e pertinência das atividades propostas.

Com o intuito de promover uma análise sistematizada do conteúdo dos roteiros de atividades pedagógicas elaborados pelos pibidianos, realizamos uma Análise de Conteúdo (BARDIN, 2016). Esse procedimento de análise foi adotado por possibilitar a realização de inferências sobre o material estudado a partir da identificação de unidades e da criação de categorias e subcategorias, permitindo assim uma compreensão mais sistematizada das partes que compõem os roteiros.

\section{RESULTADOS E DISCUSSÃo}

Ao final do minicurso foram produzidos 4 roteiros de atividades pedagógicas pelas equipes, sendo aqui representados por: R1, R2, R3 e R4. Destacamos que R1 foi elaborado conforme o quadro A e R2 de acordo com o quadro B, portanto são direcionados para o 70 ano do EF. Os R3 e R4 foram direcionados pelos quadros $\mathrm{C}$ e $\circ \mathrm{D}$, respectivamente, sendo voltados para o $8^{\circ}$ ano EF. Cabe ainda ressaltar que R1, R2 e R3 foram elaborados por equipes compostas apenas por pibidianos, e conseguinte o R4 foi resultado do trabalho da equipe constituída pelas supervisoras do subprojeto, portanto professoras que atuam na Educação Básica.

Nos propusemos inicialmente a analisar a forma que as equipes sugeriram começar a aula. Nesse aspecto observamos que R1 e R3 sugeriram fazer questionamentos para os alunos com o intuito de verificar o conhecimento prévio referente ao conteúdo a ser trabalhado, como mostrado a seguir:

- Uma interrogativa perguntando para os alunos sobre seu conhecimento sobre o conteúdo. (R1)

- Introdução do tema com perguntas direcionadas aos alunos, para que haja conhecimento prévio do saber dos mesmos sobre o assunto.

Tal proposta revela uma perspectiva de trabalho que se orienta a partir do conhecimento construído pelo aluno. Saviani (1999) afirma que a prática pedagógica deve ser iniciada com base no saber que os alunos produziram ao longo de sua vivencia social. Portanto, essa preocupação em conhecer as percepções prévias dos alunos, 
DOI: $10.12957 /$ e-mosaicos.2020.47233

constitui o primeiro passo para a mobilização desses sujeitos para a construção do saber escolar (GASPARIN, 2012).

Para Vasconcellos (1993, p. 48), esse levantamento "das representações do conhecimento dos alunos sobre o tema de estudo" corresponde ao momento de descobrir as concepções que possuem acerca do objeto a ser estudado a partir de sua percepção construída no senso comum.

Vimos assim que R1 e R3 apresentaram de modo explícito essa preocupação em saber o que os alunos trazem a respeito do conteúdo a ser trabalhado. Além disso expressaram que seria a partir dessa percepção prévia que conduziriam as atividades pedagógicas. Gasparin (2012, p. 14) afirma que "isso possibilita ao professor desenvolver um trabalho pedagógico mais adequado, a fim de que os educandos, nas fases posteriores do processo, apropriem-se de um conhecimento significativo para suas vidas".

É relevante ressaltar que a educação concebida como resultado de uma busca por conhecimentos feita por educador e educando pondera que as visões, contextos e realidades dos sujeitos devem ser consideradas no processo (FREIRE, 1978).

Destaca-se ainda que a criança carrega uma grande quantidade de informações que são construídas tanto em suas relações sociais quanto no contato com os meios de comunicação. Tal conteúdo, carregado de preconcepções acríticas, inculca os valores e concepções da cultura dominante nesses sujeitos, gerando uma reprodução do "status quo" social, representado pelas relações desiguais e de injustiça (GÓMEZ, 2000a).

Nesse contexto, quando a escola assume o compromisso de diagnosticar tais preconcepções incutidas nos alunos e as considera em seu ponto de partida no trabalho pedagógico, pode cumprir a importante tarefa de "oferecer o conhecimento público como ferramenta inestimável de análise para facilitar que cada aluno/a questione, compare e reconstrua suas preconcepções vulgares, seus interesses e atitudes direcionadas [...]" (GÓMEZ, 2000a, p. 25).

Tal perspectiva corrobora a necessidade de se investigar a situação presente em que o aluno é pertencente para assim provocar uma reconstrução crítica do seu pensamento. Portanto, R1 e R3 ao mostrarem tal cuidado dão indícios de concordar com a ideia de que o papel da escola vai além da simples reprodução de informações e que os alunos devem ser concebidos como sujeitos ativos no processo de construção de sua aprendizagem.

Em contrapartida, ao analisar a forma que R2 e R4 planejaram o início da aula, verificamos que ambas propõem o uso de uma exposição oral realizada pelo professor sobre os conceitos básicos que envolvem os conteúdos programados.

- Introdução do tema o que é atmosfera, sua composição e importância. (R2)

- As duas primeiras aulas serão para apresentação do conteúdo por meio de exposição dialogada, vídeos e animações dos movimentos da 
DOI: $10.12957 /$ e-mosaicos.2020.47233

Terra apresentados em multimídia, globo terrestre para ilustrar os movimentos terrestres. (R4)

Apesar de R2 e R4 não explicitarem na descrição qual será o sujeito que fará essa introdução do tema ou a apresentação do conteúdo, podemos deduzir que tais atividades serão realizadas pelo professor, uma vez que este detém o conteúdo sistematizado. Portanto, constituem práticas que estão mais centradas na atuação do professor, mesmo que R4 tenha indicado que tal ação seria realizada "por meio de exposição dialogada".

Importante ressaltar que ambas não expressaram nas atividades iniciais a preocupação em verificar o saber prévio dos alunos sobre os temas a serem trabalhados. Isso revela que o trabalho pedagógico poderia não estar adequado à realidade dos alunos, uma vez que o professor não teria condições de conhecer a visão de mundo destes sujeitos.

O desconhecimento acerca das "pré-ocupações" dos educandos resulta em um problema no processo de ensino e aprendizagem, pois pode possibilitar um distanciamento entre as preocupações destes sujeitos e os conteúdos escolares (GASPARIN, 2012).

Essas propostas estão atreladas a princípios que caracterizam um ensino mais tradicional. Segundo Saviani (1999) o ensino na Pedagogia Tradicional é centralizado no papel do professor, que tem a missão de transmitir os conteúdos culturalmente produzidos aos alunos e estes necessitam assimilá-los de maneira satisfatória.

Gómez (2000b), salienta que essa perspectiva está atrelada à concepção de ensino como transmissão cultural, na qual concebe como papel da escola e do professor $\mathrm{o}$ ato de transmitir os conhecimentos produzidos pela humanidade ao longo de sua história às novas gerações. Essa percepção dá maior centralidade aos "conteúdos disciplinares do que nas habilidades ou nos interesses dos alunos/as" (GÓMEZ 2000b, p. 68).

Nesse sentido, como as atividades mencionadas em R2 e R4 estão mais voltadas a imagem do professor, podemos classificá-las numa perspectiva de cunho tradicional, por desconsiderar o conhecimento prévio dos alunos.

Considerando as estratégias iniciais adotadas em cada roteiro apresentado realizamos uma primeira síntese da análise que está representada no quadro 2.

Quadro 2. Síntese das análises das estratégias iniciais dos roteiros de atividades pedagógicas.

Categoria: Características dos roteiros de atividades pedagógicas

Subcategoria 1: Estratégias iniciais: ponto de partida

\begin{tabular}{|l|c|c|}
\hline \multicolumn{1}{|c|}{ Tipo } & Número de citações & Equipes \\
\hline Considera o conhecimento prévio dos alunos & 2 & R1, R3 \\
\hline Desconsidera o conhecimento prévio dos alunos & 2 & R2, R4 \\
\hline
\end{tabular}

Fonte: Autores. 
DOI: $10.12957 /$ e-mosaicos.2020.47233

Desse modo, na subcategoria "Estratégias iniciais: ponto de partida", classificamos R1 e R3 no tipo que leva em consideração o conhecimento prévio dos alunos, atendendo a um dos requisitos de uma pedagogia crítica, enquanto que R2 e R4 foi condicionada no tipo que por desconsiderar tal conhecimento no direcionamento das práticas pedagógicas está mais alinhada a uma pedagogia de cunho tradicional.

Essa diferença reflete contrastes que estão presentes também no ambiente escolar, uma vez que concepções atreladas a uma pedagogia crítica e a uma pedagogia tradicional coexistem, mesmo que de modo conflitante, na prática pedagógica. Saviani (1999) ao abordar a história da educação brasileira, aponta os períodos em que as diferentes concepções de educação foram predominantes no país. No entanto, essa periodização não significa que tais concepções influenciaram apenas nesses momentos em específico, como algo fixo e determinado. Indicam que em cada período uma concepção foi predominante, porém suas características ainda se fazem presentes na prática pedagógica.

Posteriormente realizamos a análise sobre as estratégias de aplicação dos conteúdos ao longo das aulas. Nessa etapa percebemos uma significativa semelhança nas propostas de trabalho apresentadas por R1, R2, R3 e R4. Ao contrário da divergência observada nas formas de iniciar a aula, observamos que os quatro roteiros apresentaram a intenção de dividir a sala em grupos para a realização de atividades diversas, como mostrado a seguir.

- Divisão da sala em grupo para a apresentação de seminários que seriam eles trazerem as mudanças gerais dos biomas trabalhados em sala e as influências na fauna e na flora. (R1)

- Feira de ciências que englobam diferentes modos de representação como: maquetes, vídeos, experimentos, cartazes explicativos. (R2)

- Nas três próximas aulas os alunos serão divididos em grupo para representarem os movimentos terrestres e relacioná-los as estações do ano por meio de maquetes e protótipos. (R3)

- A exposição ocorrerá por meio de um debate realizado entre os alunos com a disposição das carteiras em círculo. (R4)

Verificamos que em todas as atividades apresentadas, os alunos assumem um papel ativo, seja na proposta de apresentação de seminários ou na participação em debates ou na elaboração de formas de representação como maquetes/cartazes/ protótipos.

Com base nas sugestões de aplicação do conteúdo realizamos uma segunda síntese de análise, pautada no tipo de atividade proposta em cada roteiro, que está representada no quadro 3. 
DOI: $10.12957 / \mathrm{e}-\mathrm{mosaicos} .2020 .47233$

Quadro 3. Síntese das análises das estratégias de aplicação dos conteúdos dos roteiros.

\begin{tabular}{|l|c|c|}
\hline \multicolumn{3}{|c|}{ Categoria: Características dos roteiros de atividades pedagógicas } \\
\hline \multicolumn{1}{|c|}{ Subcategoria 2: Estratégias de aplicação dos conteúdos } \\
\hline \multicolumn{1}{|c|}{ Tipo } & Número de citações & Equipes \\
\hline Seminário & 1 & R1 \\
\hline Formas de representação & 2 & R2, R3 \\
\hline Debate & 1 & R4 \\
\hline
\end{tabular}

Fonte: Autores.

Tais propostas poderiam oportunizar situações em que o aluno percebesse que suas preconcepções acerca dos temas trabalhados são insuficientes para a análise e resolução de situações-problema, já que estariam desafiados a solucionar problemas específicos. Essa percepção abriria a possibilidade do aluno/a se sentir provocado a buscar novos conhecimentos, voltados para uma cultura acadêmica, que gera uma reinterpretação crítica de suas preconcepções (GÓMEZ, 2000c).

Sabemos que a cultura contemporânea facilita o acesso a uma grande quantidade e diversidade de informações, o que é reforçado pela evolução tecnológica, especialmente dos meios de comunicação. No entanto, esse volume de informações está carregado de ideologias que atendem a interesses de grupos específicos da sociedade, que tem o objetivo de incutir valores, comportamentos e concepções nos sujeitos.

O excesso de estímulos e de informações muitas vezes fragmentadas e descontextualizadas, criam um "déficit na capacidade de pensar, de organizar racionalmente os fragmentos de informação[...]" (GÓMEZ 2000c, p. 63). Nesse contexto, ressalta-se a importância do papel da escola e do professor, uma vez que possuem a tarefa de trabalhar os conteúdos científicos de forma contextualizada, evidenciando que os "conteúdos são sempre uma produção histórica de como os homens conduzem sua vida nas relações sociais de trabalho em cada modo de produção" (GASPARIN, 2012, p. 2).

Assim, com o intuito de fomentar a instrumentalização dos alunos para compreenderem e atuarem de modo crítico e reflexivo na sociedade, as atividades pedagógicas devem entender os conteúdos não de modo "fragmentado, neutro, anistórico", mas como pertencentes a uma totalidade que é dinâmica e repleta de contradições (GASPARIN, 2012).

Nesse sentido, práticas que permitam a participação e envolvimento de alunos e professores, como as propostas nos roteiros criados durante o minicurso, podem promover a reflexão, análise e reconstrução de preconcepções, uma vez que produzem compartilhamento entre os sujeitos, quebrando a perspectiva de homogeneidade em relação aos alunos e enrijecimento, quanto a técnicas preestabelecidas.

Ressaltamos que o trabalho pedagógico envolve o contínuo estudo, reflexão, elaboração, avaliação e recriação do ensino. O professor é chamado a estar em permanente formação para atender às demandas e anseios que permeiam o fazer 
DOI: $10.12957 / \mathrm{e}-\mathrm{mosaicos} .2020 .47233$

pedagógico. A sociedade, constituída em suas contradições é dinâmica, o que gera ininterruptas mudanças, criando grandes desafios para a educação e consequentemente para o professor.

Assim, entendemos que a promoção de momentos que possibilitem o contato dos licenciandos com tal realidade torna-se fundamental para sua formação. O Pibid, por entender a necessidade de se investir na formação inicial dos futuros professores, tem desempenhado um papel fundamental nesse processo. Um exemplo é o trabalho proposto durante a realização do minicurso aqui relatado, que culminou na elaboração dos roteiros de atividades pedagógicas. Esses encontros promovem uma aproximação dos futuros professores da realidade e dos desafios da escola, contribuindo para um conhecimento mais real acerca do processo de ensino e aprendizagem, além de permitir um pensar crítico sobre o fazer pedagógico.

\section{CONSIDERAÇÕES FINAIS}

Destacamos a relevância desse projeto no processo de formação inicial dos futuros professores, uma vez que promove uma contínua inter-relação entre a teoria e a prática pedagógica. Além disso, evidenciamos que a participação dos licenciandos nas atividades programadas do subprojeto geram um intercâmbio de ideias e experiências, que contribuem para maturidade da formação profissional.

Relatamos uma experiência vivenciada, onde foram realizados estudos sobre a estrutura, organização e conteúdo da BNCC, voltado para o componente curricular de Ciências, séries finais do EF. Salientamos que tal estudo está previsto no programa de atividades do subprojeto e que vem a atender a necessidade de se conhecer e entender esse documento que irá nortear o trabalho pedagógico de todo o país.

Delineamos ainda a proposta desenvolvida para atrelar o conhecimento teórico acerca dos objetos de aprendizagem e habilidades presentes na BNCC e a prática pedagógica, com a elaboração de roteiros de atividades pedagógicas para alunos que cursam $07^{\circ}$ e $8^{\circ}$ do EF.

A análise do conteúdo dos roteiros permitiu perceber uma divergência de concepções acerca da forma de iniciar a aula, já que R1 e R3 consideraram a necessidade de conhecer o conhecimento prévio dos alunos e que R2 e R4 desconsideraram tal aspecto. Essa constatação evidenciou uma diferença quanto a forma de conceber o processo de ensino e aprendizagem, refletindo os contrastes presentes também nas práticas pedagógicas dos ambientes escolares.

Analisamos ainda as propostas apresentadas em cada roteiro para a aplicação dos conteúdos selecionados e verificamos uma semelhança quanto ao tipo de atividade sugerida. Observamos que todas as equipes propuseram ações que envolvessem a participação ativa dos alunos, seja por meio de organização de seminários, formas de representação ou debate. Tais atividades contribuem para a reflexão, análise e consequentemente reconstrução das preconcepções dos alunos. 
DOI: $10.12957 / \mathrm{e}-\mathrm{mosaicos} .2020 .47233$

Diante do exposto, é notável que o minicurso proposto, bem como as atividades de elaboração dos roteiros pedagógicos foram positivos no sentido de contribuir para a formação dos licenciandos. Entendemos que a participação de momentos que estimulam o pensar e o repensar a prática, bem como a reflexão e relação entre teoria e prática, são fundamentais para o processo de formação inicial dos futuros professores.

Assim, ressaltamos a relevância do projeto Pibid diante de seu papel nesse processo de formação, uma vez que proporciona aos licenciandos vivenciarem a realidade da escola de forma orientada, consistente e organizada. Percebemos que 0 subprojeto tomado como foco nesta pesquisa tem contribuído de modo positivo para a formação dos licenciandos, além de promover uma importante parceria entre a IES e as escolas de educação básica.

\section{REFERÊNCIAS}

BARDIN, L. Análise de conteúdo. São Paulo: Edições 70, 2016.

BELTRÃO, I. S. L.; KALHIL, J. B.; BARBOSA, I. S. Pibid Matemática: Contribuições para a Formação Docente. Revista do Programa de Doutorado da Rede Amazônica de Educação em Ciências e Matemática - REAMEC. Cuiabá, v. 5, n. 1, p. 78-93, jan/jun 2017.

BRASIL, Decreto-Lei no 8.752, de 9 de maio de 2016. Dispõe sobre a Política Nacional de Formação dos Profissionais da Educação Básica, 2016. Disponível em: http://www.planalto.gov.br/ccivil_03/_Ato2015-2018/2016/Decreto/D8752.htm\#art19. Acesso em: 11 de julho de 2019.

BRASIL, Portaria no 175, de 7 de agosto de 2018. Altera o Anexo I da Portaria no 45, de 12 de março de 2018, que regulamenta a concessão de bolsas e o regime de colaboração no Programa de Residência Pedagógica e no Programa Institucional de Bolsa de Iniciação à Docência (Pibid), 2018a. Disponível em:

http://pesquisa.in.gov.br/imprensa/jsp/visualiza/index.jsp?data=09/08/2018\&jornal=515 \&pagina=28. Acesso em: 11 de julho de 2019.

BRASIL, Edital n० $7 / 2018$, que torna pública a presente chamada pública para apresentação de propostas ao Programa Institucional de Bolsa de Iniciação à Docência (Pibid), Capes, 2018b. Disponível em https://www.capes.gov.br/images/stories/download/editais/01032018-Edital-7-2018PIBID.pdf. Acesso em: 10 de julho de 2019.

BRASIL, Relatório de Gestão do Exercício de 2017, da Coordenação de Aperfeiçoamento de Pessoal de Nível Superior - Capes, 2018c. Disponível em:

https://www.capes.gov.br/images/banners/18092018_Relat\%C3\%B3rio_de_Gest\%C3\% A3o_CAPES_2017.pdf. Acesso em 11 de novembro de 2019.

BRASIL, Base Nacional Comum Curricular: versão aprovada. Brasília: MEC, 2018d. 600 p. 
DOI: $10.12957 / \mathrm{e}-\mathrm{mosaicos} .2020 .47233$

BRASIL, Relatório de Gestão Pibid de 2009 a 2013, da Diretoria de Formação de Professores da Educação Básica -DEB, Capes, 2013. Disponível em:

https://capes.gov.br/images/stories/download/bolsas/1892014-relatorio-PIBID.pdf. Acesso em: 11 de novembro de 2019.

FREIRE, P. Pedagogia do Oprimido. 5. ed. Rio de Janeiro: Paz e Terra, 1978.

GASPARIN, J. L. Uma didática para a Pedagogia Histórico-Crítica. 5. ed. Campinas, SP: Autores Associados, 2012.

GÓMEZ, A. I. P. As funções sociais da escola: da reprodução à reconstrução crítica do conhecimento e da experiência. In: SACRISTÁN, J. G.; GÓMEZ, A. I. P. Compreender e transformar o ensino. Porto Alegre: Artmed: 2000a.

GÓMEZ, A. I. P. Ensino para a compreensão. In: SACRISTÁN, J. G.; GÓMEZ, A. I. P. Compreender e transformar o ensino. Porto Alegre: Artmed: 2000b.

GÓMEZ, A. I. P. A aprendizagem escolar: da didática operatória à reconstrução da cultura em sala de aula. In: SACRISTÁN, J. G.; GÓMEZ, A. I. P. Compreender e transformar o ensino. Porto Alegre: Artmed, 2000c.

MORYAMA, N.; PASSOS, M. M.; ARRUDA, S. M. Aprendizagem da Docência no PIBIDBiologia. ALEXANDRIA: Revista de Educação em Ciência e Tecnologia, Santa Catarina, v. 6, n. 3, p. 191-210, nov. 2013.

SAVIANI, D. Escola e Democracia: polêmicas do nosso tempo. 32. ed. Campinas, SP: Autores Associados, 1999.

VASCONCELLOS, C. dos S. Construção do conhecimento em sala de aula. São Paulo: Libertad, 1993.

Recebido em 10 de dezembro de 2019

Aceito em 29 de janeiro de 2020

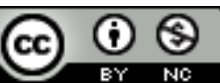

A e-Mosaicos Revista Multidisciplinar de Ensino, Pesquisa, Extensão e Cultura do Instituto de Aplicação Fernando Rodrigues da Silveira (CAp-UERJ) está disponibilizada sob uma Licença Creative Commons - Atribuição-NãoComercial 4.0 Internacional.

Os direitos autorais de todos os trabalhos publicados na revista pertencem ao(s) seu(s) autor(es) e coautor(es), com o direito de primeira publicação cedido à e-Mosaicos.

Os artigos publicados são de acesso público, de uso gratuito, com atribuição de autoria obrigatória, para aplicações de finalidade educacional e não-comercial, de acordo com o modelo de licenciamento Creative Commons adotado pela revista. 